\title{
Towards arresting reinforced concrete corrosion - a review
}

\author{
Christian Christodoulou ${ }^{1}$, Chris Goodier ${ }^{2}$, and Gareth Glass ${ }^{3}$ \\ ${ }^{1}$ AECOM Ltd, Colmore Plaza, 20 Colmore Circus Queensway, Birmingham, B4 6AT, U.K. \\ ${ }^{2}$ Loughborough University, School of Architecture, Building and Civil Engineering, Loughborough, LE113TU, U.K. \\ ${ }^{3}$ Concrete Preservation Technologies, University of Nottingham Innovation Lab, Nottingham, UK, NG7 2TU
}

\begin{abstract}
This work reviews developments in the understanding of chloride induced corrosion of steel in concrete from both a kinetic and thermodynamic perspective. Corrosion damage is at least in part attributed to the production of acid at sites of corrosion initiation. Solid phase inhibitors provide a reservoir of hydroxyl ions to inhibit damage. Pit re-alkalisation is identified as an important protective effect in electrochemical treatments used to arrest corrosion. A process like pit re-alkalisation is achieved more easily by impressing current from sacrificial anodes using a power supply which may then be followed by low maintenance galvanic protection to prevent local acidification. Methods for monitoring the steel corrosion rate in electrochemically treated reinforced concrete have been developed and used to assess corrosion risk. Some of these concepts have been adopted in the recent international standard on cathodic protection, ISO 12696:2016, some of the amendments of which are considered in the work presented here.
\end{abstract}

\section{Introduction}

Reinforced concrete (RC) structures are an essential part of society's infrastructure and the number of these types of asset has increased considerably over the last 60 years. However, their long-term performance is affected by various factors such as environmental exposure, electrochemical reactions, mechanical loading, impact damage, and others. Corrosion of the reinforcement is the main consequence for the deterioration of steel $\mathrm{RC}$ structures with the cause related to environmental exposure, poor design or construction, and others [1-3]. It is accompanied by a mass loss of rebar cross-section and a build-up of corrosion products. Very often the first indication of a problem is the appearance of a crack following the line of reinforcement. The most important causes are carbonation and chloride contamination of the concrete.

One method of arresting corrosion is to use electrochemical treatments. The application of a cathodic current to a metal surface is accompanied by a negative shift in its potential and a reduction in the over potential stimulating metal dissolution. This effect is embodied in the classical understanding of cathodic protection [4]. A cathodic current also has several other beneficial effects and much development has occurred in the field of electrochemical treatments of steel in concrete.

This work reviews developments in the understanding of chloride induced corrosion of steel in concrete from both a kinetic and thermodynamic perspective and considers the impact of these on the understanding of electrochemical treatments to arrest and prevent corrosion deterioration.

\section{Corrosion Process}

Steel in concrete is normally passive and stable, and under a high alkaline environment it develops a passive oxide protective film. Figure 1 illustrates the thermodynamic stability of the film in alkalinity. Even in the presence of chlorides, the oxides making up the protective film remain the most stable products and a significant reduction in $\mathrm{pH}$ needs to occur to de-stabilise the steel concrete system [5, 6].

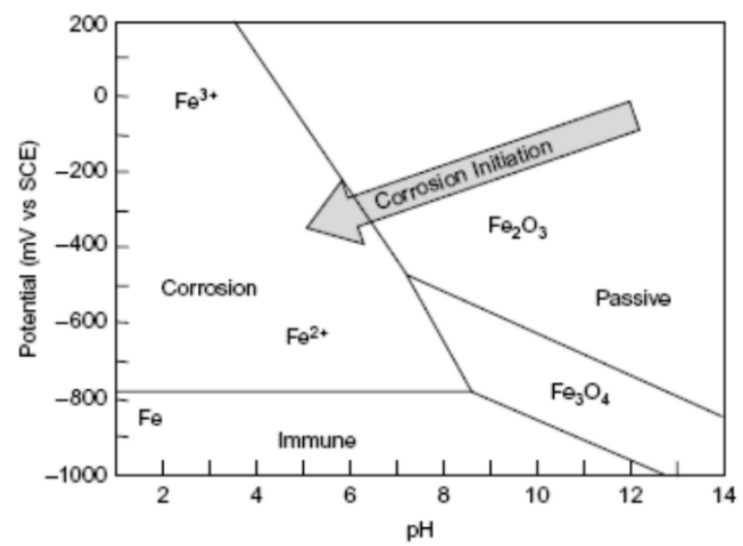

Figure 1. Corrosion initiation arrest mechanism [6]

Chloride attack tends to be localised and the film breakdown tends to follow the model of pitting corrosion followed by pit growth [7]. If the pits are to grow, pit nucleation must be followed by a fall in $\mathrm{pH}$ and increase in chloride content at the pit nucleation site. The local fall

\footnotetext{
*Corresponding author: christian.christodoulou@aecom.com
} 
in $\mathrm{pH}$ will occur from the hydrolysis of dissolving iron ions, as expressed in Equation 1.

$$
\mathrm{Fe}^{2+}+2 \mathrm{H}_{2} \mathrm{O} \rightarrow \mathrm{Fe}(\mathrm{OH})_{2}+2 \mathrm{H}^{+}
$$

The presence of an excess of chloride ions provides the charge balancing anion to stabilise the local reduction in $\mathrm{pH}$. Hydrochloric acid $(\mathrm{HCl})$ is effectively formed. Thus, the presence of chloride ions promotes the continued dissolution of iron. The process of corrosion initiation as understood in thermodynamic terms is illustrated in Figure 1.

The corrosion rate can be controlled by the kinetics of either the anodic or cathodic reactions, or by the resistance to current flow between the anodic and cathodic sites. The associated controlling mechanisms are termed anodic control, cathodic control or resistive control. Reinforced concrete is exposed to a wide variety of environments and any of these mechanisms may dominate depending on the exposure conditions [3].

When concrete is periodically allowed to dry out, oxygen has relatively easy access to the steel. The kinetics of the cathodic reaction, oxygen reduction, are said to be weakly polarised because this reaction can occur relatively easily. The presence of a passive film may restrict the overall rate by limiting the rate of metal dissolution (the anodic reaction). The anodic kinetics are said to be strongly polarised and the corrosion rate is under anodic control. To increase the corrosion rate, passive film breakdown must therefore occur $[3,5,6]$.

A typical relationship observed between the corrosion potential and the corrosion rate for a concrete exposed to chloride ion contamination in air is given in Figure 2. More negative corrosion potentials are associated with a higher corrosion risk [8].

\section{Chloride threshold}

This is defined as the critical level after which the concentration of chlorides is sufficient to sustain local breakdown of the passive film and therefore initiate

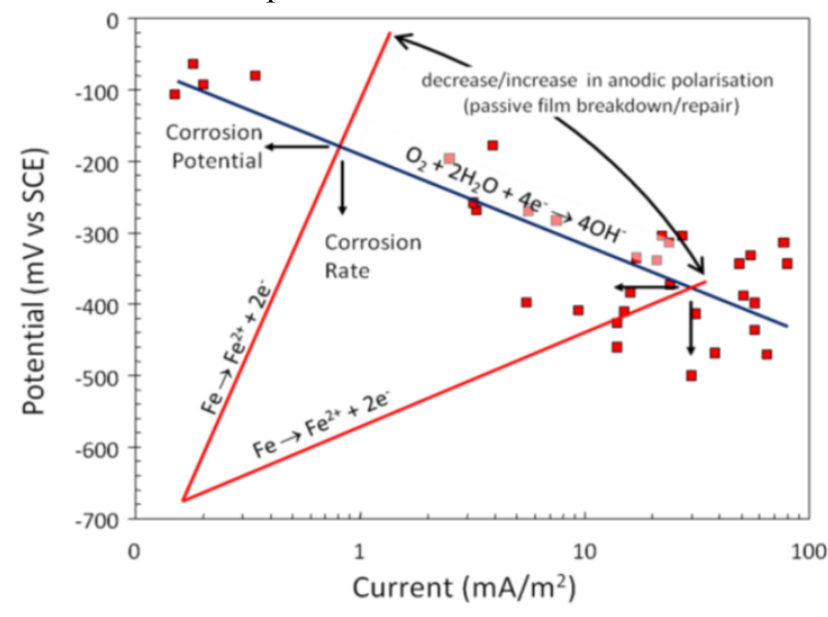

Figure 2. Relationship between potential and corrosion rate (current) in concrete exposed to air [8] micro-corrosion cells $[1,3]$. It is expressed as a ratio of the total chloride to cement content of concrete (i.e. a weight percentage).

Based on various researches and literature, typical threshold levels range between 0.2 and $2.5 \%$ by weight of cement [9]. Although chloride levels are easily measured, the cement content can only be estimated, as laboratory verification is difficult. Although bound chlorides will contribute to corrosion development, there is still not sufficient evidence to prove a correlation between the chloride binding and chloride threshold levels [10].

From the application of electrochemical treatments, it has been observed that sodium silicate gel and calcium hydroxide are by-products of the treatment which will fill the pores and the interface voids of the concrete $[11,12]$.

These will provide a reservoir of hydroxyl ions at the steel which suggests that electrochemical treatments not only arrest corrosion, but also increase the reservoir of $\mathrm{OH}-$ which then increases the chloride threshold levels.

There is strong evidence that solid phases release hydroxyl ions to inhibit corrosion initiation. Furthermore, bound chlorides may, in theory, also be released to participate in the corrosion process. Indeed, published data have, on balance, produced very little evidence of a direct relationship between chloride binding and the chloride threshold level [10].

\section{Corrosion arrest and prevention}

Arresting a chloride induced corrosion process is a problem that still presents many challenges. Chloride contaminated concrete remains at risk even after damaged areas have been repaired. Electrochemical treatments are the most proven technologies when the aim is to avoid replacing contaminated concrete but their complexity makes reliable implementation difficult. Other technologies such as drying the structure or using penetrating corrosion inhibitors may slow the corrosion process, but the effectiveness and value of these techniques is still debatable $[3,5]$.

Cathodic protection traditionally relies on achieving a negative potential shift and such a basis is in many criteria for achieving protection. A negative potential shift is induced while cathodic current is applied and is referred to as cathodic polarisation. By contrast a positive shift in the open circuit steel potential associated with anodic polarisation, results from an increase in $\mathrm{pH}$ and reduction in chloride ion content that stabilises the formation of a stable passive film (Figure 1). An improvement in the environment is generally considered to be the principal protective effect of temporary electrochemical treatments that rely on continued protection after the current is removed. However, it also appears to be the dominant protective effect during cathodic protection.

A recent study by Christodoulou et al. [13, 14] investigated the long-term benefits of early conductive coating anode Impressed Current Cathodic Protection (ICCP) systems with a view to improve the design approach, reducing maintenance requirements and ultimately reducing initial capital costs. 
It is concluded that ICCP did not only provide protection by means of a potential shift, as required by the relevant European and international standards $[15,16]$, but there that were other secondary beneficial protective effects which were probably responsible for the observed passivity and non-corroding condition of the steel reinforcement investigated in the study.

To illustrate this, the effects of a negative potential shift induced by a current of $40 \mathrm{~mA} / \mathrm{m}^{2}$ (steel surface area) are compared with a change in the environment that might induce a $200 \mathrm{mV}$ positive shift in the open circuit potential (Figure 3). The steel was initially assumed to be corroding at $30 \mathrm{~mA} / \mathrm{m}^{2}$. Figure 3 shows that a negative shift in steel potential induced by a high cathodic protection current density $\left(40 \mathrm{~mA} / \mathrm{m}^{2}\right)$ is relatively small when the steel is corroding. Indeed, it has been shown that even the application of a very high protection current density (in practical terms) cannot reverse the direction of a macrocell corrosion current on a corroding steel bar. It is postulated that the generation of hydroxyl ions at the cathode has a much more significant effect in inhibiting the corrosion process [17].

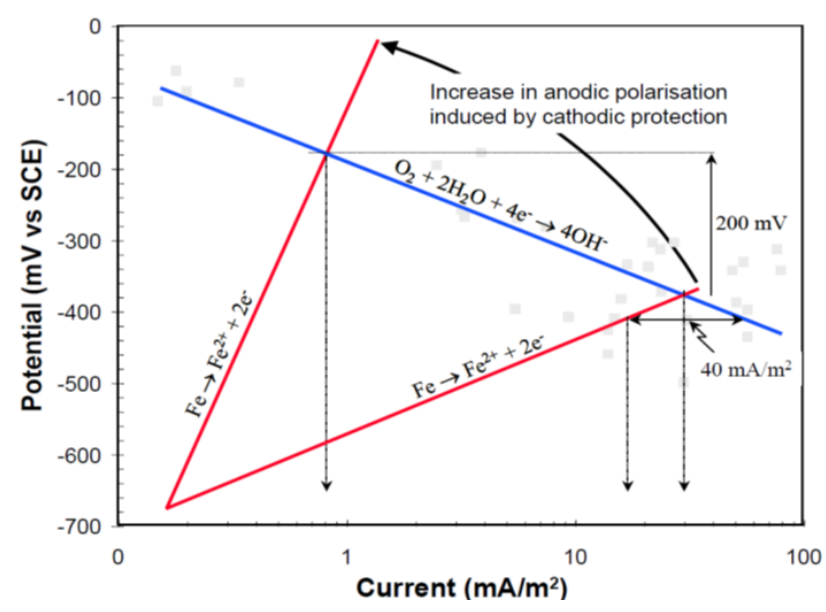

Figure 3. Comparison of the effects of a cathodic polarisation with those of anodic polarisation when the concrete is periodically allowed to dry [17].

When it comes to preventing corrosion initiation, there are two approaches that may be adopted. The first is to prevent chloride contamination of the concrete. This may, for example, be achieved by improving the barrier properties of the concrete cover, applying coatings to the concrete surface, and by removing the source of chloride [4]. The second is to increase the tolerance to chloride contamination. In this case, chloride contamination is considered to be inevitable. An increase in tolerance to chloride contamination may be achieved by changing the reinforcement material, stainless steel reinforcement being one example. Another alternative is to modify the environment immediately surrounding the steel.

\section{Electrochemical treatments}

A cathodic reduction reaction occurring on steel bars will generate hydroxyl ions there and at the same time the current will carry positive ions towards a cathode. The positive ions could include sodium, potassium and calcium and there is some evidence that soluble hydroxide compounds will form at the steel $[18,19]$.

Visual examination of electrochemically treated specimens showed a white deposit on the surfaces that received treatment (Fig. 8) [26]. The precipitation of inhibitive solid phases on the steel may be improved by adding admixtures to the concrete to improve the solubility of calcium. Calcium is not normally soluble in a high $\mathrm{pH}$ environment. The addition of calcium nitrate however, increases the soluble calcium content and therefore lowers the $\mathrm{pH}$.

Electrochemical treatments for chloride induced corrosion include cathodic protection and chloride extraction. Chloride extraction is a temporary treatment, typically for a period of 6 to 12 weeks, with typical current density of $1 \mathrm{~A} / \mathrm{m}^{2}$ and the onerous objective of removing the chloride. Higher current densities and voltages require consideration that AAR (Alkali Aggregate Reaction) may therefore take place. The anodes are only temporarily fixed to the concrete and a protective coating needs to be applied upon completion.

In contrast, cathodic protection is a permanent treatment which relies on the passage of an electric current through the electrolyte to the corroding metal surface and reverses the direction of the electric current produced by the corrosion reactions. Therefore, the potential of the metal is shifted to the negative direction.

An alternative to the above treatments are galvanic anode systems; these are not considered as powerful as cathodic protection and may not arrest an active corrosion process, although they do function in a preventative role. However, they are much simpler to install and require limited maintenance [20].

The most recent technological development in arresting an active corrosion process and maintaining steel passivity combines a brief pit re-alkalisation treatment, delivered using a power supply, with long-term galvanic protection. The pit re-alkalisation process is preferably delivered from the same sacrificial anode system used to provide galvanic protection. This novel combination is referred to as a "hybrid" electrochemical treatment [21]. It combines the power of an impressed current electrochemical treatment with the low maintenance requirements of galvanic protection. The maintenance of an impressed current treatment is limited to a brief period (weeks) during installation when steel passivity is restored.

Generally, the pit re-alkalisation process requires the delivery of relatively little charge to the steel. 30A.hrs per square meter of steel was required in a laboratory concrete specimen containing $3 \%$ chloride at the depth of the steel [21]. It is probable that less charge would be required at lower chloride contents [22].

\section{Corrosion risk management}

The new ISO standard on cathodic protection (ISO 12696:2016) [15] requires a "holistic strategy" to manage future corrosion risk in a reinforced concrete structure. In addition to empirical performance monitoring criteria the 
standard provides a platform of how to assess corrosion risk should these criteria not be achievable. A corrosion risk management plan combines monitoring with a strategy to deal with adverse monitoring data. One of these options is monitoring using corrosion rates and corrosion potential measurements.

Corrosion rates are related to the potential shift and applied current density. A common method uses polarisation theory. The polarisation behaviour (relationship between potential shift and applied current) of an electrode with activation controlled reactions is given by Equation 2,

$$
i_{\text {appl }}=i_{\text {corr }}\left(\exp \left(\frac{2.3 \Delta E}{\beta_{\mathrm{c}}}\right)-\exp \left(-\frac{2.3 \Delta E}{\beta_{\mathrm{a}}}\right)\right)
$$

where $\mathrm{i}_{\text {appl }}$ is the applied current density, $\mathrm{i}_{\text {corr }}$ is the corrosion rate, $\Delta \mathrm{E}$ is the electrode potential shift and $\beta_{\mathrm{a}}$ and $\beta_{\mathrm{c}}$ are constants [23]. In the 1950's this equation was simplified by assuming that the potential shift was small. The exponential functions were then approximated by linear functions, and the polarisation resistance method was thus developed [24]. If the potential shift is not small, the corrosion rate may still be calculated using Equation 1. The sensitivity of the calculation to errors in the various parameters has previously been assessed [25].

For steel undergoing electrochemical treatment, a conservative estimate of its potential shift is given by its potential decay measured on interrupting the protection current. Figure 4 shows an example of a corrosion rate calculated from this data [13]. In practice, the steel current density may be estimated from the current of an isolated segment of the sacrificial anode system at the location of the steel potential decay measurement.

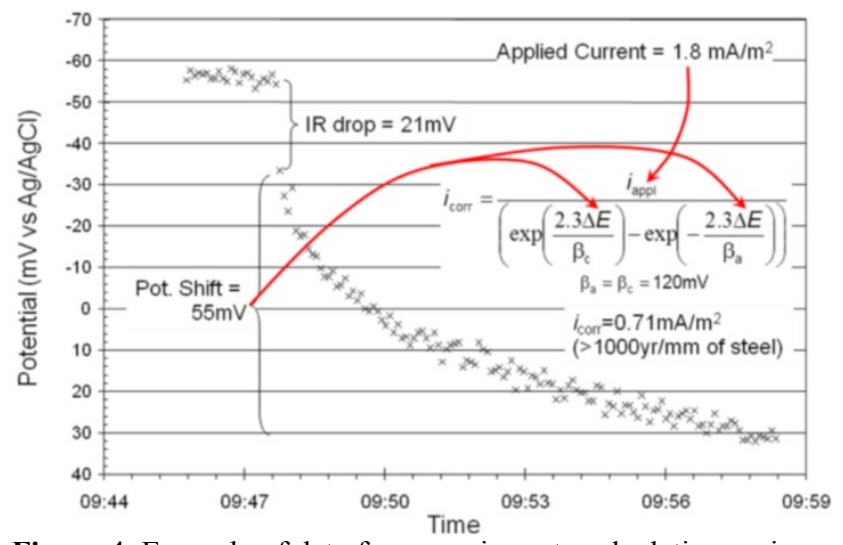

Figure 4. Example of data for corrosion rate calculations using the potential decay and applied current density [13].

\section{Conclusions}

The mechanism of chloride induced corrosion initiation on passive steel in concrete involves a reduction in the local $\mathrm{pH}$ at the site of a nucleating pit on the steel. Solids with $\mathrm{pH}$ dependent dissolution behaviour release hydroxyl and chloride ions as the local $\mathrm{pH}$ falls. Corrosion spreads from the point of initiation to adjacent steel surfaces despite the protective effects of a negative potential shift because the production of acid and the damage caused by expansive iron corrosion products overrides any protective effects of an adjacent corroding steel anode.

These effects may be considered when addressing the chloride induced corrosion risk. Chloride induced corrosion initiation will be inhibited by inhibiting the local $\mathrm{pH}$ reduction occurring during the corrosion initiation process. A major factor affecting the chloride threshold level on steel in concrete is the presence of defects at the steel-concrete interface that dilute the reservoir of inhibitive hydroxyl ions available.

Damage may be prevented by solid phase inhibitors that release hydroxyl ions to prevent a local $\mathrm{pH}$ reduction. It is in theory possible to achieve a tolerance to chloride contamination in steel reinforced concrete that is sufficiently high to effectively render the steel immune to chloride induced corrosion in many environments. A high tolerance to chloride contamination has been repeatedly obtained in laboratory concrete specimens. By reducing the entrapped air void content at the steel to values below $0.2 \%$ by volume in laboratory conditions, it was possible to increase the chloride threshold level from $0.2 \%$ to above $2 \%$ chloride by weight of cement.

A significant increase in the tolerance of steel to the presence of chloride ions in atmospherically exposed concrete may also be generated by electrochemical treatments that increase the reservoir of hydroxyl ions at the steel-concrete interface; the process is known as pit realkalisation. This breaks the acidification-iron dissolution cycle and gives rise to the time dependence of the processes leading to corrosion arrest at cathodic protection current densities as well as the positive potential shifts observed as active corrosion is arrested.

The new ISO standard on cathodic protection requires a strategy to manage future corrosion risk in a reinforced concrete structure subject to galvanic protection when substantial negative shifts are not achieved. Corrosion risk may be assessed non-destructively using corrosion potential and corrosion rate measurements. Corrosion rates may be determined from the current density delivered to the steel and the steel potential decay observed on interrupting that current.

\section{References}

1. G. K. Glass, N. R. Buenfeld, Reinforced concrete - its principles of deterioration and repair. In: Macdonald S (ed) Modern Matters Principles and Practice in Conserving Recent Architecture. Shaftesbury, UK: Donhead Publishing. 101-112 (1996)

2. British Standards Institution, BS EN 15049:2008, Products and systems for the protection and repair of concrete structures - Definitions, requirements, quality control and evaluation of conformity: Part 9. General principles for the use of products and systems, BSI, London, (2008) 
3. G. K. Glass, Deterioration of Steel Reinforced Concrete, Comprehensive Structural Integrity, Chapter 6.07, pp. 321 - 350 (2007)

4. The Concrete Society, Cathodic Protection of Steel in Concrete, Technical Report No. 73, August (2011)

5. C. Christodoulou, Electrochemical treatments of corroded reinforcement in concrete. IN: Alexander, M. et al. (eds.)Concrete Repair, Rehabilitation and Retrofitting II - Proceedings of the 2nd International Conference on Concrete Repair, Rehabilitation and Retrofitting, ICCRRR-2, 24-26 November 2008, Cape Town, South Africa, pp. 297 - 298, ISBN 978-0-41546850-3

6. G. K. Glass, B. Ready, L. Clark, Making concrete immune to chloride induced corrosion, Proceedings of the Institution of Civil Engineers, Construction Materials, 160 (4), pp. 155 - 164 (2007)

7. G. K. Glass, B. Reddy, N.R. Buenfeld, The participation of bound chloride in passive film breakdown on steel in concrete, Corrosion Science, 42, 2013-2021(2000)

8. G. K. Glass, A.M. Hassanein, N.R. Buenfeld, Cathodic protection afforded by an intermittent current applied to reinforced concrete, Corrosion Science, 43(6) 1111-1131 (2001)

9. G. K. Glass, N.R. Buenfeld, The presentation of the chloride threshold level for corrosion of steel in concrete, Corrosion Science: 39(5): 10011013 (1997)

10. G.K. Glass, B. Reddy, N.R. Buenfeld, The inhibitive properties of concrete in a chloride containing environment. 14th International Corrosion Congress, Cape Town, September 1999: Paper No 47.1 (1999)

11. T.D. Marcotte, C.M. Hansson, B.B. Hope, The effect of the electrochemical chloride extraction treatment on steel-reinforced mortar Part II Microstructural characterization. Cement and Concrete Research. 29, 1561-1568 (1999)

12. G. Sergi, C.L. Page, D.M. Thompson, Materials and Structures. 24, 359 (1991)

13. C. Christodoulou, G.K. Glass, J. Webb, S.A. Austin, C.I. Goodier, Assessing the long term benefits of Impressed Current Cathodic Protection, Corrosion Science 52, pp. 2671 (2010) - 2679 DOI information: 10.1016/j.corsci.2010.04.018

14. C. Christodoulou , A. Sharifi, S. Das, C.I. Goodier, Cathodic Protection on the UK's Midland Links motorway viaducts, Proceedings of the Institution of Civil Engineers: Bridge
Engineering, (2013), DOI information: 10.1680/bren.12.00015

15. BSI BS EN ISO: 12696-2016: Cathodic protection of steel in concrete. BSI, London, UK (2016)

16. NACE SP0290-2007, Item No. 21043, Standard Practice. Impressed Current Cathodic Protection of Reinforcing Steel in Atmospherically Exposed Structures. NACE, Houston, TX, USA (2007)

17. G. K. Glass, A.M. Hassanein, Surprisingly Effective Cathodic Protection, Journal of Corrosion Science and Engineering, 4, (2003) Paper 7.

18. T.D. Marcotte, C.M. Hansson, B.B. Hope, The effect of the electrochemical chloride extraction treatment on steel-reinforced mortar Part II Microstructural characterization, Cement and Concrete Research 29 (1999) 1561-1568.

19. J.C. Orellan, G. Escadeillas, G. Arliguie, Electrochemical chloride extraction: efficiency and side effects, Cement and Concrete Research, 34 (2), 227-234 (2004)

20. C. Christodoulou, G.K. Glass, J. Webb, V. Ngala, S. Beamish, P. Gilbert, Evaluation of galvanic technologies available for bridge structures. Presented at: Structural Faults and Repair, 12th International Conference, Edinburgh, UK, 10 -12 June (2008), $11 \mathrm{pp}$, ISBN 0-947644-62-7.

21. G.K. Glass, A.C. Roberts, N. Davison, Hybrid corrosion protection of chloride-contaminated concrete Proceedings of the Institution of Civil Engineers, Construction Materials, 161 (4) (2007) 163-172.

22. R.B. Polder, W.H.A. Peelen, B.T.J Stoop, E.A.C Neeft, Early stage beneficial effects of cathodic protection in concrete structures, Eurocorr2009, Paper 8408, (2009)

23. G.T. Burstein, A Hundred Years of Tafel's Equation: 1905-2005. Corrosion Science, 47, No. 12, p.p. 2858-2870 (2005) DOI: doi.org/10.1016/j.corsci.2005.07.002

24. B. Elsener, Corrosion rate of steel in concreteMeasurements beyond the Tafel law. Corrosion Science, 47, No. 12, p.p 3019-3033 (2005) DOI: 10.1016/j.corsci.2005.06.021

25. G.K. Glass, N.R. Buenfeld, On the current density required to protect steel in atmospherically exposed concrete structures. Corrosion Science, 37, No. 10, 1643-1646 (1995) DOI: dx.doi.org/10.1016/0010938X(95)00116-2 